\title{
Clinical and microbiologic characteristics of tcdA- negative variant clostridium difficile infections
}

\author{
Jieun Kim ${ }^{1}$, Hyunjoo Pai ${ }^{2 *}$, Mi-ran $\mathrm{Seo}^{2}$ and Jung Oak Kang ${ }^{3}$
}

\begin{abstract}
Background: The $t c d A$-negative variant $\left(\mathrm{A}^{-} \mathrm{B}^{+}\right)$of Clostridium difficile is prevalent in East Asian countries. However, the risk factors and clinical characteristics of $A^{-} B^{+} C$. difficile infections $(C D I)$ are not clearly documented. The objective of this study was to investigate these characteristics.

Methods: From September 2008 through January 2010, the clinical characteristics, medication history and treatment outcomes of CDI patients were recorded prospectively. Toxin characterization and antibiotic susceptibility tests were performed on stool isolates of $C$. difficile.

Results: During the study period, we identified 22 cases of $C D I$ caused by $t c d A$-negative tcdB-positive $\left(A^{-} B^{+}\right)$strains and 105 cases caused by $t c d A$-positive $t c d B$-positive $\left(A^{+} B^{+}\right)$strains. There was no significant difference in disease severity or clinical characteristics between the two groups. Previous use of clindamycin and young age were identified as significant risk factors for the acquisition of $A^{-} B^{+} C D I(O R=4.738,95 \% C l 1.48-15.157, p=0.009$ and $\mathrm{OR}=0.966,95 \% \mathrm{Cl} 0.935-0.998, p=0.038$, respectively) in logistic regression.

Rates of resistance to clindamycin were $100 \%$ and $69.6 \%$ in the $A^{-} B^{+}$and $A^{+} B^{+}$isolates, respectively $(p=0.006)$, and the ermB gene was identified in 17 of $21 \mathrm{~A}^{-} \mathrm{B}^{+}$isolates (81\%). Resistance to moxifloxacin was also more frequent in the $A^{-} B^{+}$than in the $A^{+} B^{+}$isolates $(95.2 \%$ vs. $63.7 \%, p=0.004)$.
\end{abstract}

Conclusions: The clinical course of $A^{-} B^{+} C D I$ is not different from that of $A^{+} B^{+} C D I$. Clindamycin use is a significant risk factor for the acquisition of tcdA-negative variant strains.

Keywords: Clostridium difficile infection, tcdA-negative variant strain, Clinical outcome, Risk factor, Antimicrobial susceptibility test, ermB gene

\section{Background}

Clostridium difficile infection (CDI) is a major cause of healthcare-associated infections worldwide. While the hypervirulent ribotype 027 strain with binary toxin has led to outbreaks only in North America and Europe $[1,2]$, toxin A-negative $\left(\mathrm{A}^{-} \mathrm{B}^{+}\right)$C. difficile infections have been reported worldwide [3-5]. The $\mathrm{A}^{-} \mathrm{B}^{+}$strain infections occur in an epidemic or sporadic form worldwide, while $\mathrm{A}^{-} \mathrm{B}^{+} \mathrm{CDI}$ is more frequent in East Asian countries [4,6-9].

Initially toxin A was considered to be the most important factor responsible for diarrheal disease [5]; however, several reports have documented that $\mathrm{A}^{-} \mathrm{B}^{+}$strains can lead to similar symptoms, from mild diarrhea to severe

\footnotetext{
* Correspondence: paihyunjoo@gmail.com

${ }^{2}$ Department of Internal Medicine, Hanyang University College of Medicine, Seoul, Korea

Full list of author information is available at the end of the article
}

pseudomembranous colitis $[10,11]$. The risk factors and clinical characteristics of $\mathrm{A}^{-} \mathrm{B}^{+} \mathrm{CDI}$ have not been clearly documented.

In this study, we investigated the presence of $\mathrm{AB}^{-}$strains in healthcare-associated CDI (HA-CDI) in Korea, compared the clinical characteristics of $\mathrm{A}^{-} \mathrm{B}^{+} \mathrm{CDI}$ and $\mathrm{A}^{+} \mathrm{B}^{+}$(tcdA-positive $t c d B$-positive) CDI, and analyzed the risk factors for acquisition of $\mathrm{AB}^{-} \mathrm{CDI}$. We also assessed the susceptibilities to clindamycin and moxifloxacin of the $\mathrm{A}^{-} \mathrm{B}^{+}$and $\mathrm{A}^{+} \mathrm{B}^{+}$strains.

\section{Methods}

\section{Setting and study design}

This study was conducted at Hanyang University Hospital, a 900-bed tertiary care facility located in Seoul, South Korea. From September 2008 through January 2010, we enrolled suspected HA-CDI patients and recorded prospectively their clinical characteristics. After isolation of C. difficile from patients' stools, microbiologic studies were 
performed. To compare the effects of 'toxin A and toxin B' strains and 'toxin B alone' strains on clinical characteristics, patients infected with $\mathrm{A}^{+} \mathrm{B}^{+}$and $\mathrm{A}^{-} \mathrm{B}^{+}$strains were enrolled, while those with binary toxin-positive isolates were excluded. This study was approved by the institutional review board of Hanyang University Hospital (HYUH IRB 2010-R-12).

\section{Definitions}

Diarrhea was defined as unformed stools more than 3 times per day on consecutive days, or 6 times within $36 \mathrm{~h}$. CDI was diagnosed when patients had diarrhea and the C. difficile stool isolates contained toxin genes detected by multiplex PCR [12]. We diagnosed HA-CDI when CDI developed at least $72 \mathrm{~h}$ after hospitalization, or within 2 months of the last discharge if the patient did spend time in a healthcare facility [13].

Clinical cure was defined as resolution of diarrhea within the treatment period, and clinical failure as the need for treatment change to resolve the diarrhea. Resolution of diarrhea required conversion to two or fewer semi-formed or formed stools per day [14]. Recurrence was defined as growth of toxinogenic $C$. difficile, a positive A\&B toxin assay (VIDAS ${ }^{\mathbb{R}}$ C. difficile Toxins A \& B; BioMerieux SA, Marcy l'Etoile, France), or a pseudomembrane on endoscopy, with resurgence of symptoms after cessation of treatment at least 10 days after the first episode [15]. Global cure was defined as clinical cure without recurrence.

\section{Collection of data}

The demographic and clinical data collected in the study were age, sex, length of hospital stay, medication history within the past 2 months, and underlying diseases including Charlson scores. Installation of a catheter, the use and dosage of antibiotics, probiotics, proton pump inhibitors, H2 blockers, steroids, chemotherapy, and surgical procedure within the past 2 months, were investigated as potential risk factors for CDI [16]. Past medication history was obtained from medical records. The amount of antibiotics administered was expressed as the number of defined daily doses (DDD), which means the total amount of antibiotic divided by the DDD [17].

Vital signs, stool character, stool frequency, and abdominal pain and tenderness were monitored within $24 \mathrm{~h}$ after inclusion. Laboratory tests such as white blood cell (WBC) count, albumin and C-reactive protein (CRP) levels were performed within 24 h of enrollment. Age $>60$ years, temperature $>38.3^{\circ} \mathrm{C}$, albumin level $<2.5 \mathrm{mg} / \mathrm{dL}$, and WBC count $>15,000$ cells $/ \mathrm{mm}^{3}$ received 1 point each, and the scores were summed for each patient. Scores above 2 were defined as severe CDI $[18,19]$.

\section{Microbiologic studies}

Stool specimens were grown anaerobically on $C$. difficileselective cycloserine-cefoxitin-taurocholate agar (CCFATA, Oxoid Ltd., Cambridge, UK), supplemented with 7\% horse blood, after alcohol shock treatment [20]. Colonies of $C$. difficile were identified with $\mathrm{API}^{\circledR}$ Rapid ID 32A (BioMerieux SA, Marcy l'Etoile, France). ATCC 43598 and PCR-ribotype 027 (BI/NAP1/027) were used as internal controls.

Template DNA from stool isolates was used in multiplex PCR to investigate the presence of toxin genes, as described elsewhere, with minor modifications [12]. After the strains producing binary toxin were excluded by multiplex PCR, toxin typing was performed [21].

Minimum inhibitory concentrations (MICs) of clindamycin and moxifloxacin were measured on supplemented Brucella agar by the E-test (AB-BIOdisc, Solna, Sweden), as recommended by the Clinical and Laboratory Standards Institute (CLSI) [22]. C. difficile ATCC 700057 was used as quality control strain for susceptibility testing.

PCR was performed on template DNA to detect the $\operatorname{erm} B$ gene [23]. A PCR product of 688 base pairs on electrophoresis was considered a positive result.

\section{Statistical methods}

SPSS version 18.0 for Windows (SPSS Inc., Chicago, IL, USA) was used for statistical analysis. Categorical variables were analysed using Pearson's chi-square test or Fisher's exact test. Continuous variables were analysed using an independent $t$-test or the Mann-Whitney $U$ test. Variables with $p$-values $<0.1$ on univariate analysis were included in the multivariate analysis. A $p$-value $<0.05$ in a two-tailed test of significance was considered statistically significant.

\section{Results}

During the study period, $138 \mathrm{C}$. difficile isolates were obtained from HA-CDI patients; 11 isolates (8.0\%) were confirmed by multiplex PCR to have binary toxin genes, 22 (15.9\%) were $\mathrm{A}^{-} \mathrm{B}^{+}$strains, and 105 (76.1\%) were $\mathrm{A}^{+} \mathrm{B}^{+}$ strains. Consequently, 22 patients with $\mathrm{A}^{-} \mathrm{B}^{+}$strains and 105 with $\mathrm{A}^{+} \mathrm{B}^{+}$strains were enrolled.

\section{Comparison of the demographic and clinical characteristics of the $\mathrm{A}^{-} \mathrm{B}^{+}$and $\mathrm{A}^{+} \mathrm{B}^{+} \mathrm{CDI}$ groups}

Demographic and clinical characteristics were compared in the $22 \mathrm{~A}^{-} \mathrm{B}^{+}$patients and the $105 \mathrm{~A}^{+} \mathrm{B}^{+}$patients (Table 1). There were no differences in age, sex, length of hospital stay, history of recent surgery or Charlson score between the two groups; however, more cases of chronic obstructive pulmonary disease (COPD) as an underlying disease were identified in the $\mathrm{A}^{-} \mathrm{B}^{+}$group $(p=0.049)$. No differences were found between the two groups with regard to factors associated with the CDI 
Table 1 Demographic and clinical characteristics of patients infected with Clostridium difficile tcdA-positive tcdBpositive $\left(A^{+} B^{+}\right)$strains and with $t c d A$-negative $t c d B$-positive $\left(A^{-} B^{+}\right)$strains

\begin{tabular}{|c|c|c|c|c|}
\hline & & $A^{+} B^{+}(n=105)$ & $A^{-} B^{+}(n=22)$ & $p$ value $^{\text {a }}$ \\
\hline Sex (female) & N (\%) & $54(51.4)$ & $8(36.4)$ & 0.244 \\
\hline Age & Mean (SD) & $65.2(15.10)$ & $58.5(19.12)$ & 0.143 \\
\hline Length of hospital stay & Mean (SD) & $34.8(44.41)$ & $24.3(21.20)$ & 0.583 \\
\hline Charlson score & Mean (SD) & $3.17(2.482)$ & $2.50(2.345)$ & 0.172 \\
\hline \multicolumn{5}{|l|}{ Underlying disease } \\
\hline COPD & N (\%) & $8(7.6)$ & $5(22.7)$ & 0.049 \\
\hline CVA & N (\%) & $28(26.7)$ & $2(9.1)$ & 0.100 \\
\hline Surgical procedure & N (\%) & $28(26.7)$ & $2(9.1)$ & 0.100 \\
\hline Severity score & Mean (SD) & $0.96(0.746)$ & $1.00(0.873)$ & 0.961 \\
\hline Old age $^{b}$ & $N(\%)$ & $67(63.8)$ & $12(54.5)$ & 0.472 \\
\hline Fever ${ }^{c}$ & $N(\%)$ & $10(9.5)$ & $5(22.7)$ & 0.137 \\
\hline Hypoalbuminemia $^{d}$ & N (\%) & $10(9.5)$ & $1(4.5)$ & 0.688 \\
\hline Leukocytosis $^{\mathrm{e}}$ & $N(\%)$ & $14(13.3)$ & $4(18.2)$ & 0.515 \\
\hline Severe $C D I^{f}$ & N (\%) & $20(19.0)$ & $4(18.2)$ & 0.925 \\
\hline \multicolumn{5}{|l|}{ Clinical findings } \\
\hline Pain & N (\%) & $25(23.8)$ & $10(45.5)$ & 0.063 \\
\hline Tenderness & $N(\%)$ & $36(34.3)$ & $10(45.5)$ & 0.338 \\
\hline Stool $\mathrm{Fr} \geq 10 /$ day & N (\%) & $21(20.4)$ & $2(9.1)$ & 0.362 \\
\hline Mucoid stool & N (\%) & $19(18.1)$ & $8(36.4)$ & 0.083 \\
\hline \multicolumn{5}{|l|}{ Laboratory findings } \\
\hline WBC (cells/mm³) & Mean (SD) & $10892(5527)$ & 10263 (7746) & 0.239 \\
\hline Albumin (mg/dL) & Mean (SD) & $3.1(0.57)$ & $3.4(0.53)$ & 0.073 \\
\hline CRP (mg/dL) & Mean (SD) & $7.40(6.397)$ & $5.98(6.194)$ & 0.139 \\
\hline Pseudomembrane $^{\mathrm{g}}$ & $\mathrm{N}(\%)$ & $10 / 26(38.5)$ & $2 / 5(40.0)$ & \\
\hline
\end{tabular}

$\mathrm{A}^{+} \mathrm{B}^{+}, t c d A$-positive $t c d B$-positive strain; $\mathrm{A}^{-} \mathrm{B}^{+}, t c d A$-negative $t c d B$-positive strain; COPD, chronic obstructive pulmonary disease; $C V A$, cerebrovascular accident; ICU,

intensive care unit; Fr, frequency; $\mathrm{CDI}$, Clostridium difficile infection; WBC, white blood cell; CRP, C-reactive protein.

${ }^{a}$ From Fisher's exact test for categorical variables or the Mann-Whitney $U$-test for continuous variables.

${ }^{b}$ Defined as age $>60$ years.

C Defined as temperature $>38.3^{\circ} \mathrm{C}$.

d Defined as albumin level $<2.5 \mathrm{mg} / \mathrm{dL}$.

e Defined as a WBC count $>15,000$ cells $/ \mathrm{mm}^{3}$

${ }^{f}$ Severity scores $>2$ points were regarded as severe CDI.

${ }^{9}$ Denominator comprises patients examined by endoscopy.

severity score. Using a definition of severe CDI adapted from Zar et al. $[18,19]$, severe CDI occurred at a similar rate in the $\mathrm{A}^{+} \mathrm{B}^{+}$and the $\mathrm{A}^{-} \mathrm{B}^{+}$group (19\% and $18.2 \%$ respectively, $p=0.925)$. WBC counts and CRP levels were higher and the albumin level lower in the $\mathrm{A}^{+} \mathrm{B}^{+} \mathrm{CDI}$ group, but these differences was not statistically significant. Clinical characteristics associated with CDI, such as stool frequency, mucoid stool, abdominal pain or tenderness, were not significantly different between the groups. The $\mathrm{A}^{-} \mathrm{B}^{+}$group was 1.067 times more likely to develop pseudomembranous colitis than the $\mathrm{A}^{+} \mathrm{B}^{+}$group, as measured by odds ratio.

Comparison of outcomes in the $\mathrm{A}^{-} \mathrm{B}^{+}$and $\mathrm{A}^{+} \mathrm{B}^{+} \mathrm{CDI}$ groups Of the 127 patients with HA-CDI, 7 were discharged before diagnosis and 3 died from an underlying disease before they had begun treatment. In 32 patients, diarrhea improved or resolved without treatment, and 85 patients $\left(16 \mathrm{~A}^{-} \mathrm{B}^{+}\right.$and $69 \mathrm{~A}^{+} \mathrm{B}^{+} \mathrm{CDI}$ cases) completed treatment $(16 / 22$ vs. $69 / 105, p=0.623)$. Treatment outcomes were compared in the two groups. The treatment regimens (metronidazole or vancomycin) did not differ significantly $(p=0.681)$. The rates of global cure, failure and mortality were respectively $62.3 \%, 5.8 \%$ and $10.1 \%$ in the $\mathrm{A}^{+} \mathrm{B}^{+}$group and $75 \%, 12.5 \%$ and $12.5 \%$ in the $\mathrm{A}^{-} \mathrm{B}^{+}$group $(p=0.398,0.315$, and 0.675 , respectively) (Table 2). One case of mortality attributable to CDI occurred in the $\mathrm{A}^{+}$ $\mathrm{B}^{+}$group. Additionally 15 of 69 patients $(21.7 \%)$ in the $\mathrm{A}^{+} \mathrm{B}^{+}$group and none in the $\mathrm{A}^{-} \mathrm{B}^{+}$group $(0 / 16)$ experienced CDI recurrence after completion of treatment; however, the difference in recurrence rate between the groups did not reach statistical significance $(p=0.063)$. 
Table 2 Comparison of clinical outcomes in patients infected with $t c d A$-positive $t c d B$-positive $\left(A^{+} B^{+}\right)$strains of Clostridium difficile and those infected with tcdA-negative tcdB-positive $\left(A^{-} B^{+}\right)$strains

\begin{tabular}{|c|c|c|c|}
\hline Clinical outcome & $\begin{array}{l}\text { Group } \\
A^{+} B^{+}(n(\%))\end{array}$ & $A^{-} B^{+}(n(\%))$ & $\begin{array}{l}p \\
\text { value }\end{array}$ \\
\hline Global cure & $43(62.3)$ & $12(75.0)$ & 0.398 \\
\hline Failure & $4(5.8)$ & $2(12.5)$ & 0.315 \\
\hline Death & $7(10.1)$ & $2(12.5)$ & 0.675 \\
\hline Recurrence & $15(21.7)$ & $0(0.0)$ & 0.063 \\
\hline Total & $69(100.0)$ & $16(100.0)$ & \\
\hline
\end{tabular}

$\mathrm{A}^{+} \mathrm{B}^{+}, t c d A$-positive $t c d B$-positive strain; $\mathrm{A}^{-} \mathrm{B}^{+}, t c d A$-negative $t c d B$-positive strain.

Clinical outcomes were not significantly different between the metronidazole and vancomycin treatment groups (measured in all patients, $p$ for trend $=0.597$ ).

\section{Comparison of previous medication history in the $A^{-} B^{+}$ and $\mathrm{A}^{+} \mathrm{B}^{+}$groups}

Medication histories of the patients were obtained by retrospective review of their medical records. After excluding 5 cases of HA-CDI due to incomplete medical records, 21 cases of $\mathrm{A}^{-} \mathrm{B}^{+} \mathrm{CDI}$ and 101 cases of $\mathrm{A}^{+} \mathrm{B}^{+}$ CDI were included in the analysis (Table 3).

Previous use of proton pump inhibitors, $\mathrm{H} 2$ blockers, probiotics, steroids or chemotherapy was not significantly different between the groups. The most commonly prescribed antibiotics in the $\mathrm{A}^{+} \mathrm{B}^{+} \mathrm{CDI}$ group were extended-spectrum cephalosporins (ESCs) (56.4\%) followed by fluoroquinolones $(45.5 \%)$ and beta-lactam/betalactamase inhibitors $(35.6 \%)$, while in the $\mathrm{A}^{-} \mathrm{B}^{+}$group they were fluoroquinolones (66.7\%), clindamycin (52.4\%) or ESCs (52.4\%). Calculating the amount of antibiotics as

Table 3 Previous medication in patients infected with $t c d A$-positive $t c d B$-positive $\left(A^{+} B^{+}\right)$strains of Clostridium difficile and with $t c d A$-negative $t c d B$-positive $\left(\mathrm{A}^{-} \mathrm{B}^{+}\right)$strains

\begin{tabular}{|c|c|c|c|c|}
\hline & & $A^{+} B^{+}(n=101)$ & $A^{-} B^{+}(n=21)$ & $P$ value $^{\mathrm{a}}$ \\
\hline \multicolumn{5}{|l|}{ Medication } \\
\hline PPI & $N(\%)$ & $35(34.7)$ & $6(28.6)$ & 0.800 \\
\hline $\mathrm{H} 2$ blockers & $N(\%)$ & $49(48.5)$ & $8(38.1)$ & 0.474 \\
\hline Probiotics & $N(\%)$ & $49(48.5)$ & $13(61.9)$ & 0.339 \\
\hline Steroids & $N(\%)$ & $37(36.6)$ & $7(33.3)$ & 1.000 \\
\hline Chemotherapy & $N(\%)$ & $12(11.9)$ & $3(14.3)$ & 0.722 \\
\hline \multicolumn{5}{|l|}{ Antibiotics } \\
\hline All-DDD & Mean (SD) & $25.4(18.91)$ & $27.0(21.83)$ & 0.989 \\
\hline Days of antibiotic use & Mean (SD) & $18.7(12.25)$ & $16.6(12.23)$ & 0.317 \\
\hline \multicolumn{5}{|l|}{ Antibiotics use } \\
\hline Fluoroquinolones & $N(\%)$ & $46(45.5)$ & $14(66.7)$ & 0.096 \\
\hline 2nd Quinolones & $N(\%)$ & $22(21.8)$ & $8(38.1)$ & 0.161 \\
\hline 3rd Quinolones & $N(\%)$ & $34(33.7)$ & $9(42.9)$ & 0.458 \\
\hline Clindamycin & $N(\%)$ & $17(16.8)$ & $11(52.4)$ & 0.001 \\
\hline ESC & $N(\%)$ & $57(56.4)$ & $11(52.4)$ & 0.811 \\
\hline $\mathrm{BL} / \mathrm{BLI}$ & $N(\%)$ & $36(35.6)$ & $6(28.6)$ & 0.620 \\
\hline Carbapenem & $N(\%)$ & $10(9.9)$ & $2(9.5)$ & 1.000 \\
\hline Glycopeptides & $N(\%)$ & $20(19.8)$ & $2(9.5)$ & 0.360 \\
\hline Metronidazole & $N(\%)$ & $29(28.7)$ & $3(14.3)$ & 0.275 \\
\hline \multicolumn{5}{|l|}{ Antibiotics dose } \\
\hline Fluoroquinolones & Mean (SD) & $5.606(9.2145)$ & $7.138(10.0394)$ & 0.202 \\
\hline 2nd Quinolones & Mean (SD) & $1.858(5.1504)$ & $2.210(4.7322)$ & 0.168 \\
\hline 3rd Quinolones & Mean (SD) & $3.737(7.2372)$ & $4.929(9.3117)$ & 0.484 \\
\hline Clindamycin & Mean (SD) & $1.111(3.1081)$ & $4.302(5.1853)$ & $<0.0001$ \\
\hline ESC & Mean (SD) & $5.260(7.7728)$ & $3.595(4.5188)$ & 0.611 \\
\hline $\mathrm{BL} / \mathrm{BLI}$ & Mean (SD) & $3.825(9.2440)$ & $3.536(8.2533)$ & 0.611 \\
\hline Carbapenem & Mean (SD) & $0.636(3.3368)$ & $0.524(1.7210)$ & 0.995 \\
\hline Glycopeptides & Mean (SD) & $1.255(3.4253)$ & $0.548(1.9359)$ & 0.270 \\
\hline Metronidazole & Mean (SD) & $2.850(6.9772)$ & $1.397(3.7901)$ & 0.194 \\
\hline
\end{tabular}

$\mathrm{A}^{+} \mathrm{B}^{+}, t c d A$-positive $t c d B$-positive strain; $\mathrm{A}^{-} \mathrm{B}^{+}, t c d A$-negative $t c d B$-positive strain; PPI, proton pump inhibitor; DDD, defined daily dose; ESC, extended-spectrum cephalosporins; BL/BLI, beta-lactam/beta-lactamase inhibitor.

${ }^{a}$ From Fisher's exact test for categorical variables or the Mann-Whitney $U$-test for continuous variables. 
DDD showed that, in the $\mathrm{A}^{+} \mathrm{B}^{+}$group, the order of antibiotics by quantity was similar to the order by frequency of use. In the $\mathrm{A}^{-} \mathrm{B}^{+}$group, antibiotics consumed in largest quantities were fluoroquinolones, clindamycin and ESCs. Finally, a comparison of previous use and amount of antibiotics in the two groups showed that both the use and amount of clindamycin were significantly higher in the $\mathrm{A}^{-} \mathrm{B}^{+}$group ( $p=0.001$ and $p<0.0001$, respectively).

\section{Risk factors for $\mathrm{A}^{-} \mathrm{B}^{+}$strain acquisition}

We performed a multivariate logistic regression analysis to identify the risk factors for acquisition of $t c d A$-negative strains. Age, sex, chronic obstructive pulmonary disease as an underlying disease, albumin level, and quinolone and clindamycin use were included in the analysis. Previous use of clindamycin was found to be a significant risk factor for $\mathrm{A}^{-} \mathrm{B}^{+}$C. difficile infection $(\mathrm{OR}=4.738,95 \%$ CI $1.481-$ $15.157, p=0.009)$. Age also had a statistically significant effect $(\mathrm{OR}=0.966,95 \%$ CI 0.935-0.998, $p=0.038)($ Table 4$)$.

\section{Microbiologic studies}

Toxinotyping was performed on the 138 isolates of $\mathrm{C}$. difficile; 104 of the $105 \mathrm{~A}^{+} \mathrm{B}^{+}$isolates (99.0\%) belonged to toxinotype 0 , and one isolate to toxinotype I; all 22 isolates of the $\mathrm{A}^{-} \mathrm{B}^{+}$strain were toxinotype VIII; 8 of 11 binary toxin-producing isolates were toxinotype IV and 3 isolates, toxinotype III.

Clindamycin and moxifloxacin susceptibility testing was performed on only 123 isolates $\left(21 \mathrm{~A}^{-} \mathrm{B}^{+}\right.$isolates and $102 \mathrm{~A}^{+} \mathrm{B}^{+}$isolates) because subculture failed in the case of 4 isolates.

The $\mathrm{A}^{-} \mathrm{B}^{+}$strains had significantly higher resistance rates to clindamycin and moxifloxacin than the $\mathrm{A}^{+} \mathrm{B}^{+}$ strains $\left(\mathrm{p}=0.006\right.$ and 0.004 , respectively). In the $\mathrm{A}^{-} \mathrm{B}^{+}$ group, the resistance rates to clindamycin and moxifloxacin were $100 \%$ (MIC range $166->256 \mathrm{mg} / \mathrm{L}$ ) and 95.2\% (MIC range $2-32 \mathrm{mg} / \mathrm{L}$ ), respectively, whereas in the $\mathrm{A}^{+} \mathrm{B}^{+}$group they were $69.6 \%$ and $63.7 \%$, respectively,

Table 4 Multivariate analysis of risk factors for tcdAnegative tcdB-positive $\left(\mathrm{A}^{-} \mathrm{B}^{+}\right)$Clostridium difficile infections

\begin{tabular}{lllll}
\hline & OR & \multicolumn{2}{l}{$\mathbf{9 5 \%}$ Cl for $\operatorname{Exp(B)}$} & p value \\
\cline { 3 - 4 } & & lower & upper & \\
\hline Age & 0.966 & 0.935 & 0.998 & 0.038 \\
\hline Sex & 1.436 & 0.482 & 4.273 & 0.516 \\
\hline Albumin & 2.584 & 0.901 & 7.412 & 0.077 \\
\hline COPD & 2.269 & 0.462 & 11.153 & 0.313 \\
\hline Fluoroquinolone use & 1.808 & 0.529 & 6.180 & 0.345 \\
\hline Clindamycin use & 4.738 & 1.481 & 15.157 & 0.009 \\
\hline OR, odds
\end{tabular}

$\mathrm{OR}$, odds ratio; $\mathrm{Cl}$, confidence interval; $\mathrm{COPD}$, chronic obstructive pulmonary disease. with wide ranges of MIC (MIC range 1.5-> $256 \mathrm{mg} / \mathrm{L}$ and $<0.25-128 \mathrm{mg} / \mathrm{L}$, respectively). Resistance to moxifloxacin was correlated with resistance to clindamycin $(\mathrm{P}<0.0001)$. The moxifloxacin resistance rate among clindamycin-resistant $\mathrm{A}^{+} \mathrm{B}^{+}$isolates was $88.7 \%(63 / 71)$ compared with $6.5 \%(2 / 31)$ among clindamycin-susceptible $\mathrm{A}^{+} \mathrm{B}^{+}$isolates. By the same token, the clindamycin resistance rate for the moxifloxacin-resistant $\mathrm{A}^{+} \mathrm{B}+$ isolates was $96.9 \%(63 / 65)$, but only $21.6 \%(8 / 37)$ for the moxifloxacin-susceptible $\mathrm{A}^{+} \mathrm{B}^{+}$isolates.

ErmB gene-specific PCR revealed that 17 of the $21 \mathrm{~A}^{-} \mathrm{B}^{+}$ isolates $(81.0 \%)$ were ermB-positive. All 17 of these isolates were resistant to clindamycin, and 16 (94.1\%) showed high level resistance (MIC $>256 \mathrm{mg} / \mathrm{L})$. Among the $102 \mathrm{~A}^{+} \mathrm{B}^{+}$ isolates, there were 49 (48.0\%) ermB-positive isolates, 37 of which (75.5\%) were highly resistant to clindamycin.

\section{Discussion}

The prevalence of toxin A-negative/toxin B-positive $\left(\mathrm{A}^{-} \mathrm{B}^{+}\right)$ strains among CDI isolates varies depending on the country. In most of Europe and in North America, the prevalence of $\mathrm{A}^{-} \mathrm{B}^{+}$strains has been reported to be only $0.2-8 \%$ $[6,24]$; however, such strains are thought to have caused several outbreaks in those regions. For example, in Poland the prevalence of $\mathrm{AB}^{-} \mathrm{B}^{+}$strains has increased from $11 \%$ to $45 \%$ [25] since there was an outbreak. By contrast, Japan has reported a high prevalence of $\mathrm{A}^{-} \mathrm{B}^{+}$strains; the peak incidence was $39 \%$ in 2000 [10], and the incidence decreased to $12.7 \%$ in $2005-2008$ [8]. A report from Shanghai revealed that $\mathrm{A}^{-} \mathrm{B}^{+}$strains were responsible for a third of all CDI cases [4]. In Korea, the frequency of $\mathrm{A}^{-} \mathrm{B}^{+}$strains was reported to be $4.9 \%$ in 1998 [26], and it then increased to $50.9 \%$ in $2004-2005$ [7,11]. In our study, the frequency of $\mathrm{A}^{-} \mathrm{B}^{+}$strains among the HA-CDI patients in 2009 was $15.9 \%$. Even given the expected fluctuations in time and space, such a high frequency of $\mathrm{A}^{-} \mathrm{B}^{+}$strains over the East Asian region is interesting. Possible explanations could be similar profiles of antibiotic use, and spread of the pathogen through common foods, as well as the heavy traffic of people across the three countries.

The role of toxin A and toxin B in the pathogenecity of CDI has been debated. Although early studies suggested that toxigenic strains of $C$. difficile always produce both toxin A and toxin B [5], one study showed that toxin $B$ is the key virulence factor [27]. However, a recent study figured out that $C$. difficile producing either one or both toxins showed cytotoxic activity in vitro that translated directly into virulence in vivo [28]. Several studies of the clinical characteristics of $\mathrm{A}^{-} \mathrm{B}^{+} \mathrm{CDI}[8,29-31]$ have shown that $\mathrm{A}^{-} \mathrm{B}^{+}$strains cause a wide spectrum of diseases from asymptomatic colonization to life-threatening colitis [31], and that there is no significant difference between the clinical manifestations and outcomes of CDI caused by 
$\mathrm{A}^{-} \mathrm{B}^{+}$and $\mathrm{A}^{+} \mathrm{B}^{+}$strains [10]. However, another study reported more cases of pseudomembranous colitis on endoscopy in $\mathrm{A}^{-} \mathrm{B}^{+}$patients than in $\mathrm{A}^{+} \mathrm{B}^{+}$patients $(70 \%$ vs. $40 \%, p=0.0016$ ) [11]. Furthermore, severe CDI caused by PCR ribotype 017 was responsible for $5 \%$ of cases in Germany, and all these cases had lethal outcomes [30]. In another report, the mortality during a PCR ribotype 017 CDI outbreak attributable to that ribotype was similar to that attributable to PCR ribotype 027 (7.0\% vs. 6.5\%), and higher than that attributable to other types (7.0\% vs. $1.6 \%)$ [32]. Conversely, in our study there was no significant difference in the clinical characteristics, the laboratory findings or the incidence of pseudomembranous colitis between the study groups, and there were no deaths attributable to $\mathrm{A}^{-} \mathrm{B}^{+} \mathrm{CDI}$. The clinical outcomes also did not differ in the two groups, although there was no $\mathrm{A}^{-} \mathrm{B}^{+} \mathrm{CDI}$ recurrence. In previous reports, the recurrence rate of $\mathrm{A}^{-} \mathrm{B}^{+} \mathrm{CDI}$ varied from 9 to $35.7 \%$ and was similar to that of $\mathrm{A}^{+} \mathrm{B}^{+}$ CDI $[3,29]$. The reason that we observed no recurrence and no attributable death could be simply that the number of $\mathrm{A} \mathrm{B}^{+}$cases in this non-epidemic setting was too low. $\mathrm{Al}$ ternatively it could be because the $\mathrm{A}^{-} \mathrm{B}^{+} \mathrm{CDI}$ developed in younger patients with lower Charlson scores, or because the shorter hospital stays among the $\mathrm{A}^{-} \mathrm{B}^{+}$group prevented re-infection (however that effect was not statistically significant). Another possibility is that $\mathrm{A}^{-} \mathrm{B}^{+} \mathrm{CDI}$ recurs less frequently than $\mathrm{A}^{+} \mathrm{B}^{+} \mathrm{CDI}$. To investigate this, a further study with a larger number of cases would be necessary.

In order to confirm that clindamycin use is an important risk factor for $\mathrm{A}^{-} \mathrm{B}^{+} \mathrm{CDI}$ in a clinical setting, we compared the antimicrobial susceptibilities of the $\mathrm{A}^{-} \mathrm{B}^{+}$and $\mathrm{A}^{+} \mathrm{B}^{+}$ strains. As expected [33], all $21 \mathrm{~A}^{-} \mathrm{B}^{+}$strains were resistant to clindamycin. High level resistance to clindamycin $(\mathrm{MIC}>256 \mathrm{mg} / \mathrm{L})$ in $C$. difficile is usually linked to the erm $B$ gene, encoding resistance to macrolide-lincosamidestreptogramin $\mathrm{B}\left(\mathrm{MLS}_{\mathrm{B}}\right)$ [31]. In this study, the percentage of ermB-positive strains was $53.7 \%$ among all $C$. difficile isolates and $81.0 \%$ among the $\mathrm{A}^{-} \mathrm{B}^{+}$isolates. Among the $\mathrm{A}^{-}$ $\mathrm{B}^{+}$strains, 4 of the 21 isolates were $\operatorname{erm} B$-negative, and all of these were highly resistant to clindamycin. Clindamycin resistance in these strains could also be induced by other mechanisms such as other erm genes, efflux mechanisms, or nucleotide substitutions in other genes [34]. Further study of these resistance mechanisms would be desirable.

In previous studies, moxifloxacin resistance was closely associated with clindamycin resistance (95\% CI 68-97\%) $[34,35]$. It was reported that, of isolates resistant to fluoroquinolones, $98 \%$ were resistant to either erythromycin or clindamycin, although fluoroquinolone resistance in the absence of $M L S_{B}$ resistance was rare [35]. Similarly, in our study, resistance to moxifloxacin was highly correlated with clindamycin resistance $(p<0.0001)$. An efflux pump may be responsible for the co-resistance to the $M_{L} S_{B}$ drugs and fluoroquinolone.

\section{Conclusions}

The prevalence of $\mathrm{A}^{-} \mathrm{B}^{+}$strains among $\mathrm{HA}-\mathrm{CDI}$ patients in Korea was $15.9 \%$. Disease severity and clinical characteristics were not significantly different between the $\mathrm{A}^{-} \mathrm{B}^{+}$ and the $\mathrm{A}^{+} \mathrm{B}^{+}$patients. Previous use of clindamycin is a risk factor for acquisition of an $\mathrm{A}^{-} \mathrm{B}^{+}$strain, and all tested $\mathrm{A}^{-} \mathrm{B}^{+}$isolates were highly resistant to clindamycin. Heavy use of clindamycin appears to facilitate $\mathrm{A}^{-} \mathrm{B}^{+}$strain infection in our hospitals.

\section{Competing interests}

The authors declare that they have no competing interests.

\section{Acknowledgments}

This work was supported by a grant from the National Research Foundation of Korea (KRF-2011-0014685). Moxifloxacin E-test strips (AB-BIOdisc, Solna, Sweden) were kindly provided by BioMerieux SA, Korea.

Presented in part at the $51^{\text {st }}$ Interscience Conference on Antimicrobial Agents and Chemotherapy (ICAAC); Sept. 17-20, 2011, Chicago (slide K1716)

\section{Author details}

${ }^{1}$ Department of Internal Medicine, Hanyang University College of Medicine, Guri, Korea. ${ }^{2}$ Department of Internal Medicine, Hanyang University College of Medicine, Seoul, Korea. ${ }^{3}$ Department of Laboratory Medicine, Hanyang University College of Medicine, Guri, Korea.

\section{Authors' contributions}

J Kim contributed to protocol preparation, data collection and analysis, as well as manuscript preparation. H Pai provided the funding for this study and made a major contribution to the interpretation of data and appraisal of the manuscript. M Seo participated in the microbiologic studies, and J O Kang contributed to the microbiologic studies, discussion of results and revision of the manuscript. All authors read and approved the final manuscript.

Received: 8 November 2011 Accepted: 9 May 2012

Published: 9 May 2012

\section{References}

1. Warny M, Pepin J, Fang A, Killgore G, Thompson A, Brazier J, Frost E, McDonald LC: Toxin production by an emerging strain of Clostridium difficile associated with outbreaks of severe disease in North America and Europe. Lancet 2005, 366:1079-1084.

2. Clements AC, Magalhaes RJ, Tatem AJ, Paterson DL, Riley TV: Clostridium difficile PCR ribotype 027: assessing the risks of further worldwide spread. Lancet Infect Dis 2010, 10:395-404.

3. Goorhuis A, Legaria MC, van den Berg RJ, Harmanus C, Klaassen CH, Brazier JS, Lumelsky G, Kuijper EJ: Application of multiple-locus variable-number tandem-repeat analysis to determine clonal spread of toxin A-negative Clostridium difficile in a general hospital in Buenos Aires, Argentina. Clin Microbiol Infect 2009, 15:1080-1086.

4. Huang $H$, Wu S, Wang $M$, Zhang $Y$, Fang $H$, Palmgren $A C$, Weintraub $A$, Nord CE: Clostridium difficile infections in a Shanghai hospital: antimicrobial resistance, toxin profiles and ribotypes. Int J Antimicrob Agents 2009, 33:339-342.

5. 'Lyerly DM, Krivan HC, Wilkins TD: Clostridium difficile: its disease and toxins. Clin Microbiol Rev 1988, 1:1-18.

6. Bauer MP, Notermans DW, van Benthem BH, Brazier JS, Wilcox MH, Rupnik M, Monnet DL, van Dissel JT, Kuijper EJ: Clostridium difficile infection in Europe: a hospital-based survey. Lancet 2011, 377:63-73.

7. Kim H, Riley TV, Kim M, Kim CK, Yong D, Lee K, Chong Y, Park JW: Increasing prevalence of toxin A-negative, toxin B-positive isolates of Clostridium difficile in Korea: impact on laboratory diagnosis. J Clin Microbiol 2008, 46:1116-1117.

8. Iwashima Y, Nakamura A, Kato H, Wakimoto Y, Wakiyama N, Kaji C, Ueda R: A retrospective study of the epidemiology of Clostridium difficile infection at a University Hospital in Japan: genotypic features of the isolates and clinical characteristics of the patients. J Infect Chemother 2010, 16:329-333. 
9. Elliott B, Squire MM, Thean S, Chang BJ, Brazier JS, Rupnik M, Riley T: New types of toxin A-negative, toxin B-positive strains among clinical isolates of Clostridium difficile in Australia. J Med Microbiol 2011, 10:10

10. Komatsu M, Kato H, Aihara M, Shimakawa K, Iwasaki M, Nagasaka Y, Fukuda S, Matsuo S, Arakawa Y, Watanabe M, Iwatani Y: High frequency of antibiotic-associated diarrhea due to toxin A-negative, toxin B-positive Clostridium difficile in a hospital in Japan and risk factors for infection. Eur J Clin Microbiol Infect Dis 2003, 22:525-529.

11. Shin BM, Kuak EY, Yoo SJ, Shin WC, Yoo HM: Emerging toxin A-B + variant strain of Clostridium difficile responsible for pseudomembranous colitis at a tertiary care hospital in Korea. Diagn Microbiol Infect Dis 2008, 60:333-337.

12. Persson S, Torpdahl M, Olsen KE: New multiplex PCR method for the detection of Clostridium difficile toxin $A(t c d A)$ and toxin $B(\operatorname{tcd} B)$ and the binary toxin ( $c d t A / c d t B)$ genes applied to a Danish strain collection. Clin Microbiol Infect 2008, 14:1057-1064.

13. Mulvey MR, Boyd DA, Gravel D, Hutchinson J, Kelly S, McGeer A, Moore D, Simor A, Suh KN, Taylor G, et al: Hypervirulent Clostridium difficile strains in hospitalized patients, Canada. Emerg Infect Dis 2010, 16:678-681.

14. Louie T, Miller M, Donskey C, Mullane K, Goldstein EJ: Clinical outcomes, safety, and pharmacokinetics of OPT-80 in a phase 2 trial with patients with Clostridium difficile infection. Antimicrob Agents Chemother 2009, 53:223-228

15. Barbut F, Richard A, Hamadi K, Chomette V, Burghoffer B, Petit JC: Epidemiology of recurrences or reinfections of Clostridium difficileassociated diarrhea. J Clin Microbiol 2000, 38:2386-2388.

16. O'Connor JR, Johnson S, Gerding DN: Clostridium difficile infection caused by the epidemic BI/NAP1/027 strain. Gastroenterology 2009, 136:1913-1924.

17. World Health Organisation: The anatomical therapeutic chemical (ATC) and defined daily dosing (DDD) system index 2010.: ; [http://www.whocc.no/].

18. Zar FA, Bakkanagari SR, Moorthi KM, Davis MB: A comparison of vancomycin and metronidazole for the treatment of Clostridium difficileassociated diarrhea, stratified by disease severity. Clin Infect Dis 2007 , 45:302-307.

19. Fujitani S, George WL, Murthy AR: Comparison of Clinical Severity Score Indices for Clostridium difficile Infection. Infect Control Hosp Epidemiol 2011, 32:220-228.

20. Clabots CR, Gerding SJ, Olson MM, Peterson LR, Gerding DN: Detection of asymptomatic Clostridium difficile carriage by an alcohol shock procedure. J Clin Microbiol 1989, 27:2386-2387.

21. Rupnik M, Avesani V, Janc M, von Eichel-Streiber C, Delmee M: A novel toxinotyping scheme and correlation of toxinotypes with serogroups of Clostridium difficile isolates. J Clin Microbiol 1998, 36:2240-2247.

22. Clinical and Laboratory Standards Institute: Methods for antimicrobial susceptibility testing of Anaerobic bacteria; Approved standard, 7th edition. Wayne, PA, USA: CLSI document M11-A7; 2007.

23. Johnson S, Samore MH, Farrow KA, Killgore GE, Tenover FC, Lyras D, Rood I, DeGirolami P, Baltch AL, Rafferty ME, et al: Epidemics of diarrhea caused by a clindamycin-resistant strain of Clostridium difficile in four hospitals. $N$ Engl J Med 1999, 341:1645-1651.

24. Cheknis AK, Sambol SP, Davidson DM, Nagaro KJ, Mancini MC, HidalgoArroyo GA, Brazier JS, Johnson S, Gerding DN: Distribution of Clostridium difficile strains from a North American, European and Australian trial of treatment for C. difficile infections: 2005-2007. Anaerobe 2009, 15:230-233.

25. Pituch $H$, Obuch-Woszczatynski P, Wultanska D, Nurzynska G, Harmanus C, Banaszkiewicz A, Radzikowski A, Luczak M, van Belkum A, Kuijper E: Characterization and antimicrobial susceptibility of Clostridium difficile strains isolated from adult patients with diarrhoea hospitalized in two university hospitals in Poland, 2004-2006. J Med Microbiol 2011, 60:1200-1205.

26. Chung Y, Chung GT, Seong WK, Oh HB: Molecular Analysis of Clostridium difficile Isolates by Arbitrarily Primed-Polymerase Chain Reaction and Polymerase Chain Reaction-Ribotyping. Korean J Infect Dis 2002, 34:167-175.

27. Lyras D, O'Connor JR, Howarth PM, Sambol SP, Carter GP, Phumoonna T, Poon R, Adams V, Vedantam G, Johnson S, et al: Toxin B is essential for virulence of Clostridium difficile. Nature 2009, 458:1176-1179.

28. Kuehne SA, Cartman ST, Heap JT, Kelly ML, Cockayne A, Minton NP: The role of toxin A and toxin B in Clostridium difficile infection. Nature 2010, 467:711-713.

29. Alfa MJ, Kabani A, Lyerly D, Moncrief S, Neville LM, Al-Barrak A, Harding GK, Dyck B, Olekson K, Embil JM: Characterization of a toxin A-negative, toxin B-positive strain of Clostridium difficile responsible for a nosocomial outbreak of Clostridium difficile-associated diarrhea. J Clin Microbiol 2000, 38:2706-2714

30. Arvand M, Hauri AM, Zaiss NH, Witte W, Bettge-Weller G: Clostridium difficile ribotypes 001, 017, and 027 are associated with lethal $C$. difficile infection in Hesse, Germany. Euro Surveill 2009, 14:19403.

31. Drudy D, Fanning S, Kyne L: Toxin A-negative, toxin B-positive Clostridium difficile. Int J Infect Dis 2007, 11:5-10.

32. Goorhuis A, Debast SB, Dutilh JC, van Kinschot CM, Harmanus C, Cannegieter SC, Hagen EC, Kuijper EJ: Type-Specific Risk Factors and Outcome in an Outbreak With 2 Different Clostridium difficile Types Simultaneously in 1 Hospital. Clin Infect Dis 2011, 53:860-869.

33. Pituch $H$, Van Belkum A, Van Den Braak N, Obuch-Woszczatynski P, Verbrugh $H$, Meisel-Mikolajczyk F, uczak M: Recent emergence of an epidemic clindamycin-resistant clone of Clostridium difficile among Polish patients with C. difficile-associated diarrhea. J Clin Microbiol 2003, 41:4184-4187.

34. Ackermann G, Degner A, Cohen SH, Silva J Jr, Rodloff AC: Prevalence and association of macrolide-lincosamide-streptogramin $B(M L S(B))$ resistance with resistance to moxifloxacin in Clostridium difficile. J Antimicrob Chemother 2003, 51:599-603.

35. Solomon K, Fanning S, McDermott S, Murray S, Scott L, Martin A, Skally M, Burns $K$, Kuijper E, Fitzpatrick $F$, et al: PCR ribotype prevalence and molecular basis of macrolide-lincosamide-streptogramin B (MLSB) and fluoroquinolone resistance in Irish clinical Clostridium difficile isolates. J Antimicrob Chemother 2011, 66:1976-1982.

doi:10.1186/1471-2334-12-109

Cite this article as: Kim et al:: Clinical and microbiologic characteristics of $t c d A$-negative variant clostridium difficile infections. BMC Infectious Diseases 2012 12:109.

\section{Submit your next manuscript to BioMed Central and take full advantage of:}

- Convenient online submission

- Thorough peer review

- No space constraints or color figure charges

- Immediate publication on acceptance

- Inclusion in PubMed, CAS, Scopus and Google Scholar

- Research which is freely available for redistribution 